\title{
PSYCHOPATHOLOGY IN OFFSPRING OF PARENTS WITH BIPOLAR DISORDER IN AN EGYPTIAN SAMPLE
}

\section{Safeya Mahmoud Effat*, Nahla Elsayed Nagy*, Dalia Abdel Moneim Mahmoud*, and Asmaa Abdelwahab Eissa Ahmed**}

Institute of Psychiatry, The WHO Collaborating Center for Mental Health Research and Training, Ain Shams University, Department of Neuropsychiatry, Cairo, Egypt* Abbasseyia Mental health hospital, 1 salah salem street, Cairo, Egypt**.

Corresponding author Asmaa Abdelwahab Eissa Ahmed Mobile: (+2) 01111429069 E.mail:

drasma2009@yahoo.com

Received: 27/1/2021

Accepted: 18/2/2021

\section{Online ISSN: 2735-3540}

\begin{abstract}
:
Background: Offspring of parents with Bipolar affective disorder are at risk for a spectrum of future psychiatric disorders. Although the link between family functioning and children's development remained well-established, there is a small research examining whether family factors play a role in helping children with behavior problems outgrow their difficulties.
\end{abstract}

Aim of the work: The current study was to identify the risk factors that contributes to the development of psychiatric morbidity, to identify the nature of psychiatric morbidity that affects these children.

Patients and methods: A sample consist of 200 participants was recruited and divided into 100 offspring of parents diagnosed with bipolar affective disorder using SCID-I, patients were selected from either new or follow up cases, who were attending the outpatient clinics, psychiatry department, Ain Shams University Hospitals) And 100 offspring of parents with irrelevant psychiatric history. Children were also evaluated by The Child Behavior Checklist (CBCL) to screen for psychopathology.

Results: offspring of parents with Bipolar affective disorder are at increased risk of developing a wide range of psychiatric disorders and accompanying dysfunction than offspring of healthy or non-BP parents. the most prevalent behavior among cases was attention problems $75 \%$, aggression $63 \%$, social problem $48 \%$

Conclusion: These findings demonstrated the Offspring of $B D$ are at significantly higher risk of developing a broad range of affective and non-affective psychopathology when compared to control offspring.

Keywords: bipolar disorder, psychopathology, CBCL, offspring.

\section{INTRODUCTION:}

Bipolar affective disorder (BD) is a neuropsychiatric disorder characterized by extreme fluctuations mood shifts alternating between episodes of mania and depression (1). Depressive episodes are associated with sad mood, suicidality, impaired cognition, and anhedonia whereas Manic symptoms include decreased sleep, high-risk actions, and impulsivity. So, the estimated lifetime prevalence of $\mathrm{BD}$ is 1 to 3 percent worldwide $^{(2,3)}$. There is evidence of genetic influences explaining $60-85 \%$ of risk inherited of mood disorder from family members referring a potentially large genetic contribution to the disorder ${ }^{(4)}$.

Genetic factors in bipolar affective disorder tends to be familiar, about half the people with Bipolar affective disorder have family member with a mood disorder, such as depression, ADHD. The person who has one parent with bipolar disorder has a 15 to 
$25 \%$ chance of having the incidence. A person who has a non-identical twin with the disorder has a $25 \%$ chance of disorder, the same risk as if both parents have BD. A person who has an identical twin with Bipolar affective disorder has an even higher risk of developing the disorder about an eight-fold higher risk than a non-identical twin $^{(5)}$.

It is generally held that the offspring of parents with Bipolar affective disorder are at risk for a spectrum of future psychiatric disorders. The degree of risk is an important question for both clinicians and parents. These risks involving conduct disorders, learning problems, neuropsychological deficits, and high rates of internalizing problems. Although the link between family functioning and children's development remained well-established, there is a small research examining whether family factors play a role in helping children with behavior problems outgrow their difficulties. Even rarer are studies that examine factors which predict how well children with behavior problems develop emotionally, socially, and academically, over time. Since children with behavior problems are at risk for a host of negative outcomes. It is critical to identify factors that might increase risk among these children. Parents' psychopathology is one aspect of family functioning that is thought to play an important role in children's development ${ }^{(6)}$.

Compared with the offspring of both psychiatric and non-psychiatric comparison parents, the offspring of bipolar parents showed elevated rates of anxiety disorders, involving anxiety disorder, separation anxiety disorder, and overanxious disorder. Moreover, anxiety disorders in the high-risk offspring were significant predictors of the subsequent onset of diagnosable mood disorders. Given that the BD typically debuts as depressive disorders in high-risk offspring, the finding that anxiety disorders did not exactly predict BD is not unexpected
That is, the cohort are still in the period of risk for manifesting the index activated episode $^{(7,8)}$.

In sum, these parent-child relationships may protect against the impact of genetic vulnerability for BD. Family communication training, problem-solving and behavioral parenting strategies have shown positive consequences in symptom remission in highrisk offspring ${ }^{(9)}$

Additionally, mood liability, anxiety, attention difficulties, hyper-arousal, depression, somatic complaints, and school problems display more symptoms in offspring of bipolar disorder parents than controls, also dysthymic, cyclothymic, or hyperthymic temperaments may presage eventual in bipolar disorder offspring ${ }^{(10)}$

Thus, BD offspring were estimated to be 2.5 times more at risk to develop any psychiatric disorder and four times more at risk to have a mood disorder but, perspective studies in preschool children submitted a prevalence eight times higher for the presence of ADHD, as well as increased frequency of sub-threshold manic and depressive $\mathrm{BD}^{(11)}$

\section{PATIENTS AND METHODS:}

\section{Site of the study}

Participants were selected from the outpatient clinics at the Institute of Psychiatry, Ain Shams University Hospitals. The study was conducted in accordance with the guidelines of the Research and Ethics Committee of the Institute of Psychiatry, Ain Shams University.

\section{Study design}

It is a Case- Control study comparative study by convenience sampling.

\section{Subjects:}

A total number of 200 hundred children from participants were recruited and divided 
into: One hundred offspring of parents diagnosed with bipolar affective disorder according to diagnostic and statistical Manual of Mental disorders, 4th edition (DSM IV) was recruited from 8- 12 years old, Egyptians only. Another One hundred offspring of selected volunteer healthy parents without any history suggestion of any psychiatric symptoms from 8- 12 years old, Egyptians only.

\section{Procedures}

1- Informed consent: A written consent was obtained from them after explaining the objectives of the study.

2- Arabic version of Structured Clinical Interview for DSM-IV-TR Axis I Disorders $\left(\right.$ SCID-I) ${ }^{(12)}$ : for clinical assessment and diagnosis of substance use disorder and exclude other psychiatric disorders.

3- The Child Behavior Checklist $(\mathrm{CBCL})^{(13)}$. Arabic version by ${ }^{(14)}$. to assess of The Children's Psychopathology.

\section{Measurments}

\section{1) Structured Clinical Interview for DSM-IV (SCID I) ${ }^{(12)}$.}

The study used the Arabic version of the structured clinical interview for DSM-IV axis I diagnosis (SCID-I). It is a semistructured diagnostic interview which has been updated for DSM-IV ${ }^{(15)}$. It begins with a section on demographic information and clinical background. Then there are 7 diagnostic modules, focused on different diagnostic groups: mood, psychotic, substance abuse, anxiety, somatoform, eating and adjustment disorders. It is applied to the case group to diagnose drug Dependence and exclude other Axis I diagnosis.

\section{2) The Child Behavior Checklist (CBCL) $^{(13,14)}$.}

The Child Behavior Checklist are questionnaires to be completed, respectively, by parents, and adolescents themselves and can be scored on eight syndrome scales (Withdrawn, Somatic Complaints, Anxious/ Depressed, Social Problems, Thought Problems, Attention Problems, Delinquent Behavior and Aggressive Behavior), and two broad-band groupings of syndromes: Internalizing (consisting of the first three scales), and Externalizing (consisting of the last two scales) The Child Behavior Checklist-school age version (CBCL) was completed by the primary caregiver. The scale includes 118 problem behavior items rated on a Likert scale from zero (not true) to two (true or frequently true). We used the two broadband subscales (Internalizing and Externalizing) and the six DSM-IV oriented subscales (Affective Problems, Anxiety Problems, Somatic Problems, Attention Deficit/ Hyperactivity Problems, Oppositional Defiant Problems and Conduct Problems)

\section{3) Statistical analysis.}

All data was tabulated, grouped, and statistically analyzed using (SPSS 20) (Statistical Package for the Social Sciences) on a compatible PC (personal computer). Data was presented, and suitable analysis was done according to the type of data obtained for each parameter. For descriptive statistics: Mean, Standard deviation ( \pm SD) and range for parametric numerical data. while Median and Interquartile range (IQR) for non-parametric numerical data. Frequency and percentage of non-numerical data. Analytical statistics: Student T Test was used to assess the statistical significance of the difference between two study group means. For analytical statistics: Pearson Chi Square Test $\left(\chi^{2}\right)$ : was used to assess the statistical significance of the difference between two study group means. Fisher's exact test was used to examine the relationship between two qualitative variables when the expected count is less than 5 in more than $20 \%$ of cells and $\mathbf{P}$ value: Used to indicate the level of significance: $\mathrm{P}>0.05$ : Nonsignificant, $\mathrm{P}<$ 
0.05: Significant, $\mathrm{P}<0.01$ : Highly significant and $\mathrm{P}<0.001$ : Very highly significant.

\section{RESULTS:}

\section{Socio-demographic characteristics:}

Descriptive analysis of the sociodemographic and clinical data of the parents of the children in the whole sample: The general characteristics of the studied participants showed no statistically significant difference between both groups for age (P-value >0.05). Most of the parents in the study were mothers in both cases and control groups (72\%, $78 \%$ respectively). There appeared to no statistically significant difference between any of the general characteristics of both cases \& control, only the sex of parent showed a statistical difference between the parent was a mother or a father which can be attributed to the fact the mothers exceed the father's number in the study's sample.

Table (1): General characteristics of the studied participants ( $n=200)$.

\begin{tabular}{|c|c|c|c|c|c|c|c|c|}
\hline \multirow{2}{*}{\multicolumn{2}{|c|}{ Participants }} & \multicolumn{2}{|c|}{ case } & \multicolumn{2}{|c|}{ Control } & \multicolumn{3}{|c|}{ test of significance } \\
\hline & & \multirow{2}{*}{$\begin{array}{l}\mathrm{N} \\
55\end{array}$} & \multirow{2}{*}{$\begin{array}{c}\% \\
55.00 \%\end{array}$} & \multirow{2}{*}{$\begin{array}{l}\mathrm{N} \\
53\end{array}$} & \multirow{2}{*}{$\begin{array}{c}\% \\
53.00 \% \\
\end{array}$} & \multirow{3}{*}{$\begin{array}{c}\text { Value } \\
\mathrm{X}^{2}= \\
0.08\end{array}$} & \multirow{3}{*}{$\begin{array}{l}\mathrm{p} \text { value } \\
0.777\end{array}$} & \multirow{3}{*}{$\begin{array}{l}\text { sig. } \\
\text { NS }\end{array}$} \\
\hline Child & Male & & & & & & & \\
\hline (male/female) & Female & 45 & $45.00 \%$ & 47 & $47.00 \%$ & & & \\
\hline \multirow{4}{*}{ Birth-order } & 1 & 44 & $44.00 \%$ & 44 & $44.00 \%$ & \multirow{4}{*}{$\begin{array}{c}\text { Fisher } \\
\text { exact } \\
\text { test }\end{array}$} & \multirow{4}{*}{$>0.999$} & \multirow{4}{*}{ NS } \\
\hline & 2 & 41 & $41.00 \%$ & 41 & $41.00 \%$ & & & \\
\hline & 3 & 14 & $14.00 \%$ & 14 & $14.00 \%$ & & & \\
\hline & 4 & 1 & $1.00 \%$ & 1 & $1.00 \%$ & & & \\
\hline \multirow{3}{*}{ Marital status } & Married & 76 & $76.00 \%$ & 78 & $78.00 \%$ & \multirow{3}{*}{$\begin{array}{c}\text { Fisher } \\
\text { exact } \\
\text { test }\end{array}$} & \multirow{3}{*}{0.867} & \multirow{3}{*}{ NS } \\
\hline & Divorced & 23 & $23.00 \%$ & 22 & $22.00 \%$ & & & \\
\hline & widow & 1 & $1.00 \%$ & 0 & $0.00 \%$ & & & \\
\hline \multirow{5}{*}{ Mother Education } & illiterate & 18 & $18.00 \%$ & 19 & $19.00 \%$ & \multirow{5}{*}{$\begin{array}{c}\text { Fisher } \\
\text { exact } \\
\text { test }\end{array}$} & \multirow{5}{*}{0.711} & \multirow{5}{*}{ NS } \\
\hline & $\begin{array}{c}\text { Primary } \\
\text { school }\end{array}$ & 20 & $20.00 \%$ & 19 & $19.00 \%$ & & & \\
\hline & $\begin{array}{l}\text { secondry } \\
\text { school }\end{array}$ & 14 & $14.00 \%$ & 18 & $18.00 \%$ & & & \\
\hline & Graduate & 28 & $28.00 \%$ & 30 & $30.00 \%$ & & & \\
\hline & Postgraduate & 19 & $19.00 \%$ & 14 & $14.00 \%$ & & & \\
\hline \multirow{5}{*}{ Father Education } & illiterate & 8 & $8.00 \%$ & 10 & $10.00 \%$ & \multirow{5}{*}{$\begin{array}{c}\text { Fisher } \\
\text { exact } \\
\text { test }\end{array}$} & \multirow{5}{*}{0.766} & \multirow{5}{*}{ NS } \\
\hline & $\begin{array}{c}\text { Primary } \\
\text { school }\end{array}$ & 13 & $13.00 \%$ & 11 & $11.00 \%$ & & & \\
\hline & $\begin{array}{c}\text { secondry } \\
\text { school }\end{array}$ & 25 & $25.00 \%$ & 26 & $26.00 \%$ & & & \\
\hline & Graduate & 29 & $29.00 \%$ & 31 & $31.00 \%$ & & & \\
\hline & Postgraduate & 25 & $25.00 \%$ & 22 & $22.00 \%$ & & & \\
\hline \multirow{2}{*}{$\begin{array}{c}\text { Parent } \\
\text { (father/mother) }\end{array}$} & father & 28 & $28.00 \%$ & 24 & $24.00 \%$ & \multirow{2}{*}{$\begin{array}{l}\mathrm{X}^{2}= \\
4.20\end{array}$} & \multirow{2}{*}{0.041} & \multirow{2}{*}{$S$} \\
\hline & mother & 72 & $72.00 \%$ & 78 & $78.00 \%$ & & & \\
\hline
\end{tabular}

Table (2): Sub-type of the bipolar disorder among parents.

\begin{tabular}{|c|c|c|c|}
\hline \multirow{2}{*}{ Participants } & \multirow{2}{*}{ Type } & \multicolumn{2}{|c|}{ Bipolar disorder parents } \\
\cline { 2 - 4 } & & $\mathrm{N}$ & $\%$ \\
\hline \multirow{2}{*}{ Bipolar disorder type } & $\mathrm{I}$ & 40 & $40.0 \%$ \\
\cline { 2 - 4 } & $\mathrm{II}$ & 60 & $60.0 \%$ \\
\hline duration of disorder by years & & 11.7 & 3.3 \\
\hline
\end{tabular}

Table (2) shows that most of the bipolar parents $(60 \%)$ had bipolar type II, while
(40\%) had type I. The mean disease duration was $11.7 \pm 3( \pm \mathrm{SD})$. 
Diagram (1): The type of bipolar among the studied parents $(\mathrm{N}=200)$.

\section{Type of bipolar}

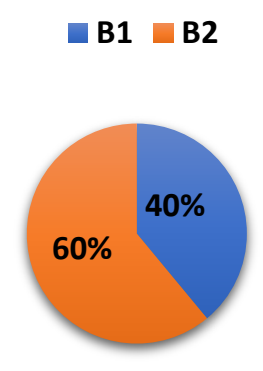

Diagram 1: shows that $60 \%$ of recruited cases has bipolar type II while $40 \%$ had bipolar type I.

Comparing the Child Behavior Checklist scores of the children among both groups.

The Child Behavior Checklist (CBCL) showed no statistically significant difference between both cases and control groups for withdrawn domains (P-value
$>0.05)$, while statistically significant differences were observed between both groups (P-value <0.05) in the other domains, as shown in table (3) and figure (2).

Table (3): The Child Behavior Checklist (CBCL) among the whole sample of participants $(n=200)$

\begin{tabular}{|c|c|c|c|c|c|c|c|}
\hline \multirow{2}{*}{ Participants } & \multicolumn{2}{|c|}{ Case } & \multicolumn{2}{|c|}{ control } & \multicolumn{3}{c|}{ test of significance } \\
\cline { 2 - 9 } & $\mathrm{N}$ & $\%$ & $\mathrm{~N}$ & $\%$ & Value & $\mathrm{p}$ value & sig. \\
\hline Anxious & 42 & $42.00 \%$ & 20 & $20.00 \%$ & $\mathrm{X}^{2}=11.31$ & 0.001 & $\mathrm{~S}$ \\
\hline Withdrawn & 11 & $11.00 \%$ & 8 & $8.00 \%$ & $\mathrm{X}^{2}=0.52$ & 0.469 & $\mathrm{NS}$ \\
\hline Somatic Complaints & 0 & $0.00 \%$ & 4 & $4.00 \%$ & Fisher exact test & 0.121 & $\mathrm{NS}$ \\
\hline Social Problems & 48 & $48.00 \%$ & 15 & $15.00 \%$ & $\mathrm{X}^{2}=25.24$ & $<0.001$ & $\mathrm{~S}$ \\
\hline Thought Problems & 28 & $28.00 \%$ & 4 & $4.00 \%$ & $\mathrm{X}^{2}=21.43$ & $<0.001$ & $\mathrm{~S}$ \\
\hline Attention Problems & 75 & $75.00 \%$ & 30 & $30.00 \%$ & $\mathrm{X}^{2}=40.60$ & $<0.001$ & $\mathrm{~S}$ \\
\hline Rule Breaking Problems & 37 & $37.00 \%$ & 11 & $11.00 \%$ & $\mathrm{X}^{2}=18.53$ & $<0.001$ & $\mathrm{~S}$ \\
\hline Aggressive & 63 & $63.00 \%$ & 24 & $24.00 \%$ & $\mathrm{X}^{2}=30.94$ & $<0.001$ & $\mathrm{~S}$ \\
\hline Other problems & 47 & $47.00 \%$ & 9 & $9.00 \%$ & $\mathrm{X}^{2}=35.81$ & $<0.001$ & $\mathrm{~S}$ \\
\hline
\end{tabular}

Table (3) showed that, the cases vs control groups showed $(42 \%$ and $4 \%$ respectively) in somatic complaints. moreover, the case group showed higher scores in anxious symptoms. For social problems, the cases group had more social problem scores $(48 \%)$ than the control group (15\%). 


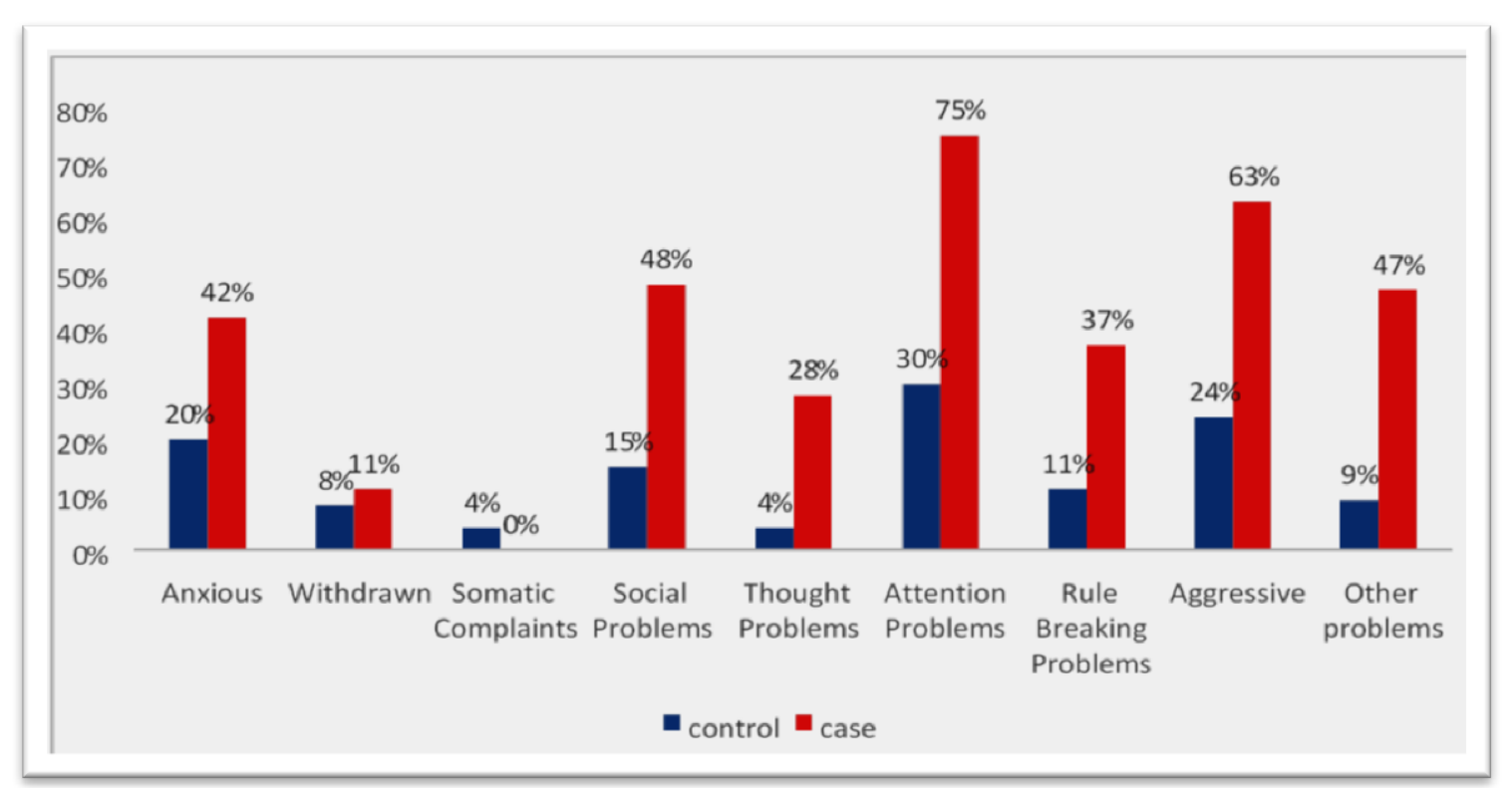

Diagram (2): The comparison in Child Behavior Checklist (CBCL) among the studied participants and control $(\mathrm{N}=200)$

Diagram (2): shows that the most prevalent behavior among both cases and controls was attention problems $(75 \%, 30 \%$ respectively) and least was somatic problems which was absent among cases and present in $4 \%$ of controls.

\section{DISCUSSION:}

When studying the sociodemographic of the study sample, our findings revealed that, no statistically significant difference in marital status between the 2 groups the bipolar parent's group were married $76.0 \%$, divorced $23.0 \%$, widow $1.0 \%$ while the control parent's group married $78.0 \%$, divorced $22.0 \%$. Most of the bipolar parents $(60 \%)$ had bipolar type II, while (40\%) had type I. The disease duration was $11.7 \pm 3$. Also, Ranning and colleagues (16) study showed that the OBP with BP-I had significantly higher rates of BP-I. And offspring of parents with BP-II had significantly higher rates of BP-II in offspring, although this difference did not reach statistical significance in entire age group. The etiology and clinical course of $\mathrm{BP}$ are determined by genetic and environmental factors. The same in our present study showed that the older mother's or father's age does not affect the incidence of disease (P-value <0.05). but there appears to be a significant correlation between age of the child (The mean \pm SD 10.0 \pm 1.5 ). and the development of anxiety disorders. Yet, it is not apparent to be due to the father's or the mother's age. It can be explained by considering that anxiety disorders can be particularly the prodrome of mood disorder in childhood. On evaluating predictive factors, we found by using The Child Behavior Checklist (CBCL) showed no statistically significant difference between both groups for anxious and withdrawn, while $43 \%$ of the sample were diagnosed as Social problems, but Aggressiveness was the most prevailing diagnosis with $82 \%$ followed by attention problems with $67 \%$, generalized anxiety disorder with $33 \%$, while Rule Breaking Problems with $31 \%$. And, as regarding somatic complaints all the control group was normal while $17 \%$ of the study group were borderline.

Limaa and colleagues ${ }^{(17)}$ found that the offspring of bipolar parents are at serious risk of being affected by mood disorders. Additionally, data from existing longitudinal studies of the offspring of bipolar parents 
have proved that the first manic phase is generally preceded by depressive symptoms. So, Studies focusing on the offspring of affected parents, frequently referred to as the high-risk study design, utilize the wellestablished familial aggregation of mood disorders as a powerful tool for the identification of risk factors, early clinical manifestations and prodromes of mood disorders in these offspring.

Of note, Bobo (2017) (18) study's findings from high-risk studies specific to BD pro-bands, which controlled for potential confounding factors have shown that the offspring of $\mathrm{BD}$ pro-bands are at much higher risk for MDD, BD, and ADHD than controls. Parents' sociodemographic factors and Bipolar affective disorder history in relation to their offspring's psychopathology. Breaux and colleagues found that the offspring of parents with BP-I were higher risk for BP-I, with a morbidity risk of $13.8 \%$ by age 17 . These findings are like those of other studies (20.7\%), supporting the hypothesis that relatives of pro-bands BP-I have increased risk of suffering BP-I.

Colorations in anxious symptoms between BP offspring and offspring of control McDonald and Schwanz ${ }^{(19)}$ assumed that the subgroup of offspring of BD who will develop major affective disorders in adulthood will have inherited a tendency for high levels of neuroticism. So, in our present study, we found that the cases of our sample $(42,0 \%, n=42)$ had anxious symptoms on CBCL scale while the control was $(20,0 \%, n=20)$ and this finding is interesting and statistically significant. Also, the results of our study supported the hypothesis that diathesis of bipolar disorder itself includes a risk of anxiety. This finding is particularly noticeable given studies in both adults and children with bipolar affective disorder that observed high rates of comorbidity with anxiety disorders, especially panic disorder, GAD, and obsessive-compulsive disorder. Also, we found that the only factor significant among cases is the age of OBD. Additionally, Ellenbogen \&colleagues ${ }^{(20)}$ found that BD offspring that present with symptoms of depression, anxiety and/or ADHD at a young age appear to be at highest risk for developing BD. Also, Moreno and colleagues (21) found early onset of an anxiety disorder remained to be the most consistent and reliable indicator of subsequent affective disorder in BD highrisk subjects. A pre-existing anxiety disorder among high-risk offspring more than doubled the risk of having a major affective disorder approximately 8 years after the initial diagnosis, even after adjusting for parental anxiety and behavioral disorders. But, in Merikukkaa et al. ${ }^{(22)}$ study showed that there were no statistically significant differences between the two groups for anxiety and withdrawal (P-value> 0.05). This finding was proven by life pressures and increased level of anxiety in the nonbipolar offspring as the bipolar offspring. Also, in Zavaleta-Ramírez et al., ${ }^{(23)}$ study Anxiety disorders occurred more frequently in children of non-bipolar parents. There finding was $71 \%$ of offspring of non-bipolar parents' verses $58 \%$ of offspring of bipolar parents that was related to an increased sensitivity to parents' recognition of psychopathology when accepting that their children were assessed. Biederman and colleagues $^{(24)}$ noted that, the presence of anxiety disorder in biological parents was associated with psychopathology in the offspring of BP, but this meant that it was lost after controlling for bipolar diagnosis. Chorot and colleagues ${ }^{(25)}$ observed that, offspring with anxiety diagnoses were more likely to have a history of both BD mothers and BD fathers. Although these results were not statistically significant (i.e., P-value < 0.05 ) for offspring of BD fathers, this may be a result of limited power given the similar effect sizes between offspring of BD mothers and $\mathrm{BD}$ fathers. A relationship between offspring control cases and 
subsequent offspring anxiety remained observed in preceding studies of offspring of parents with and without psychopathology.

\section{Colorations in withdrawal symptoms between BP offspring and control}

In our study showed no statistically significant difference between both groups for withdrawn with mean $( \pm$ SD) $60.3 \pm 7,2$ in cases and $61,4 \pm 6,6$ in control. this finding may be demonstrated by the stressors of life was increased the technology lifestyle in non-bipolar offspring as bipolar offspring. Although, Dilsaver and colleagues (26) pointed out that aspects of the parent-child relationship are related to the ease with which the offspring infiltrates leaving the home leaving the home, and there is much less research examining how pathological psychology or parental impairment affects this process. Studies have documented that caregivers with mental health problems are more withdrawn from their offspring and show less and more hostile sensitivity to them. Additionally, parents with BD depend on their offspring to provide them with emotional and instrumental care-taking more than other caregivers. Thus, because parents with affective disorders may be more dependent on their children, they may be less likely to help guide and support the emerging adult's navigation of the leaving home transition. ${ }^{(27)}$

Role of funding source: The authors of this manuscript declare that no funding bodies were involved in sponsoring or funding this research.

Conflicts of interest: Disclosure of conflict of interest: All authors declare no actual or potential conflict of interest whether financial, personal or otherwise related to this manuscript.

\section{REFERENCES:}

1. Craddock N. \&Sklar P. (2013). Genetics of BD. The Lancet. journal 381:1654-1662.
2. Barnett J., \&Smoller J. (2009). The Genetics of BD. Neuroscience journal. 164:331-343.

3. Pedersen C., Mors O., Bertelsen A., Waltoft B., et al. (2014). A comprehensive nationwide study of the incidence rate and lifetime risk for treated mental disorders. JAMA Psychiatry journal. 71(5):573-81.

4. Senda T., Bardtkea S., Gilles M., Wolf I., et al. (2019). Stress reactivity in preschoolaged children: Evaluation of a social stress paradigm and investigation of the impact of prenatal maternal stress Psychoneuroendocrinology journal 101:223-231.

5. Goretti M., Covadonga M., Díaz-Caneja E., lisa R., et al., (2017). A developmental approach to dimensional expression of psychopathology in child and adolescent offspring of parents with bipolar disorder. Eur Child Adolescent Psychiatry journal 26:1165-1175.

6. Breaux R., Harvey E. \&Lugo-Candelas C. (2013). The Role of Parent Psychopathology in the Development of Preschool Children with Behavior Problems. journal Clinical Child Adolescent Psychology. 1-14.

7. Havinga P., Hartman C., Visser E., Nauta M., et al. (2018). Offspring of depressed and anxious patients: Help-seeking after first onset of a mood and anxiety disorder journal of Affective Disorders 227; 618626.

8. Perich T., Lau P., Hadzi-Pavlovic D., Roberts G., et al. (2015). What clinical features precedes the onset of BD? journal Psychiatric. Research. 62, 71-77.

9. Essaua C., Sasagawab S., Lewinsohnc P., Rohdec P. (2018). The impact of pre- and perinatal factors on psychopathology in adulthood journal of Affective Disorders 236: 52-59.

10. Sugranyes G., de la Serna E., Borras R., Sanchez-Gistau V., et al. (2017). Clinical, Cognitive, and Neuroimaging Evidence of a Neurodevelopmental Continuum in Offspring of Probands With Schizophrenia and Bipolar Disorder Schizophrenia Bulletin journal 43:6 (1208-1219). 
11. Wesseldijk L., Dieleman G., Steensel F., Bartels M., et al. (2018). Risk factors for parental psychopathology: a study in families with children or adolescents with psychopathology European Child \& Adolescent Psychiatry journal 27:15751584.

12. First, Michael B., Spitzer, Robert L, Gibbon Miriam, and Williams, Janet B.W. (1996). Structured Clinical Interview for DSM-IV Axis I Disorders, Clinician Version (SCID-CV). Washington, D.C.: American Psychiatric Press, Inc., 1996.

13. Achenbach T., \&Edelbrock C. (1983). Manual for the Child Behavior Checklist and Revised Child Behavior Profile. Burlington: University of Vermont Department of Psychiatry.

14. El-Defrawi M. H. (1997). Psychiatric disorders in a sample of Egyptian preschool children. Egyptian journal of Psychiatry, 20, 271-282.

15. American Psychiatric Association Diagnostic and statistical manual of mental disorders DSM-IV-TR, 2000.Text Revision 4th edn. American Psychiatric Association.

16. Ranning A., Laursen T., Agerbo E., Thorup A., et al., (2018). School performance from primary education in the adolescent offspring of parents with schizophrenia and bipolar disorder- a national, register-based study. Psychology Medicine journal 48(12):1993-2000.

17. Limaa A., Peckhama A., \&Johnsona S. (2018). Cognitive deficits in bipolar disorders: Implications for emotion. Clinical Psychology Review journal. 59: 126-136.

18. Bobo W. (2017). The Diagnosis and Management of Bipolar I and II Disorders: Clinical Practice Update a 2017 Mayo Foundation for Medical Education and Research n Mayo Clinical Proc journal. 2017;92(10):1532-1551.

19. McDonald S.\& Schwanz L. (2018). Thermal parental effects on offspring behavior and their fitness consequences Animal Behavior journal $135 ; 45 \mathrm{e} 55$.
20. Ellenbogen M., Linnen A., Holy J.,het Rot M., et al. (2013).Young e Salivary cortisol and interpersonal functioning: An eventcontingent recording study in the offspring of parents with bipolar disorder Psychoneuroendocrinology journal 38, 997-1006.

21. Moreno D., Bio D., Petresco S., Petresco D., et al. (2012). A Burden of maternal bipolar disorder on at-risk offspring: A controlled study on family planning and maternal care journal. of Affective Disorders 143; 172-178.

22. Merikukkaa M., Räsänenc S., Hakkoc H., Ristikari T. et al. (2018). Parental hospitaltreated somatic illnesses during offspring's childhood associated with later offspring use of psychotropic medication during childhood to young adult — The 1987 Finnish Birth Cohort study Preventive Medicine journal 111:254-264.

23. Zavaleta- Pamírez, de la Peña F, FeriaAranda M, Mora L et al. (2014): Comparative study of psychopathology among bipolar offspring. Salud Mental journal 37(6):477-482.

24. Biederman J., Mick E., Faraone S., Spencer T., et al., (2000): Pediatric mania: A developmental subtype of bipolar disorder? Biol Psychiatry Journal 48:458-466.

25. Chorot P., Valiente R., Magaz A., Santed M. \&Sandin B. (2017). Perceived parental child rearing and attachment as predictors of anxiety and depressive disorder symptoms in children: The mediational role of Attachment Psychiatry Research journal. 253: 287-295.

26. Dilsaver S., Henderson-Fuller S., Akiskal H. (2003): Occult mood disorders in 104 consecutively presenting children referred for the treatment of attentiondeficit/hyperactivity disorder in a community mental health clinic. Clinical Psychiatry journal 1170-1176.

27. Doughty C., Wells J., Joyce P., Olds R., Walsh A. (2004): Bipolar-panic disorder comorbidity within bipolar disorder families: A study of siblings. Bipolar Disorder journal 6:245-252. 


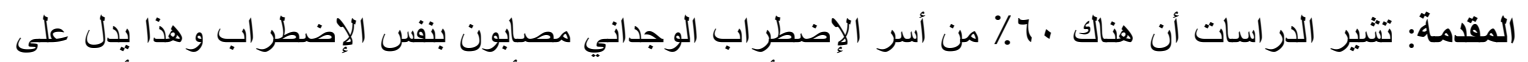

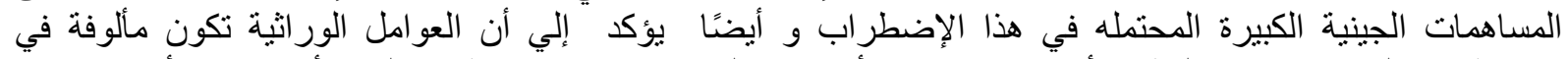

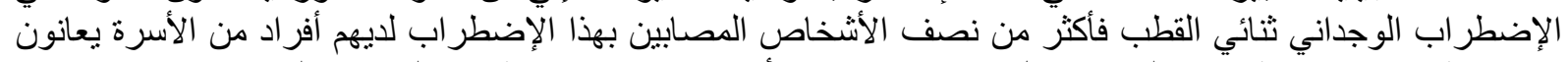

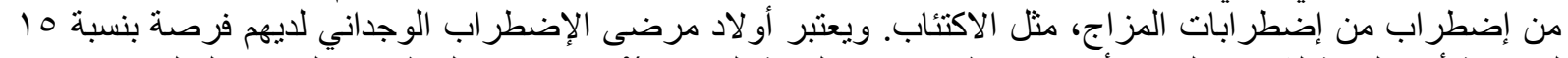

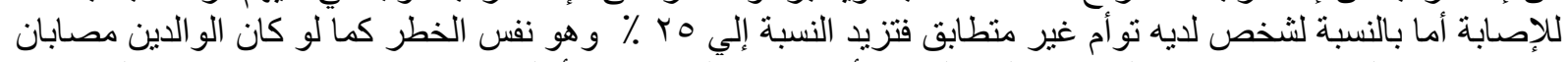

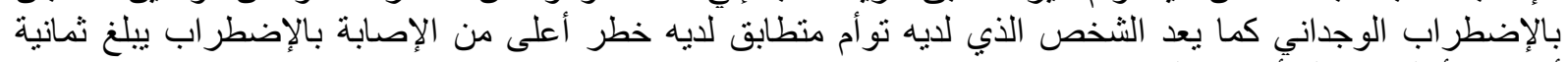

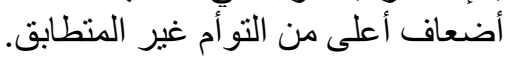

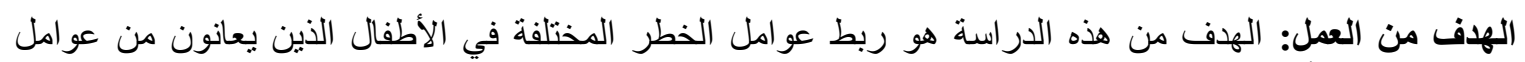

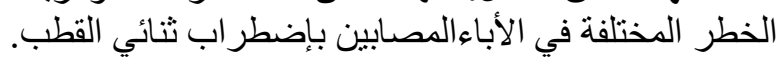

$$
\text { في الإضطر اب الوجداني ثنائي القطب. }
$$

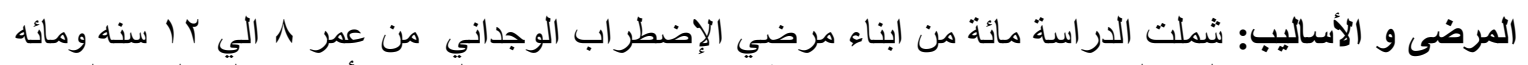

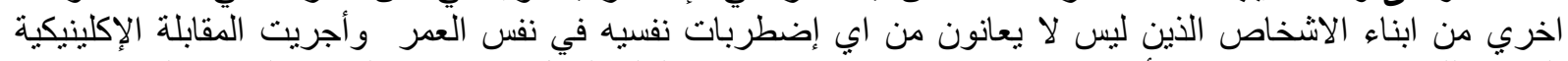

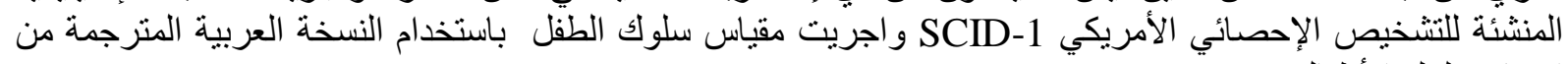
اختبار سلوك الأطفال . الإحست.

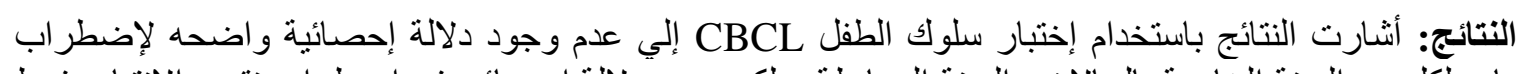

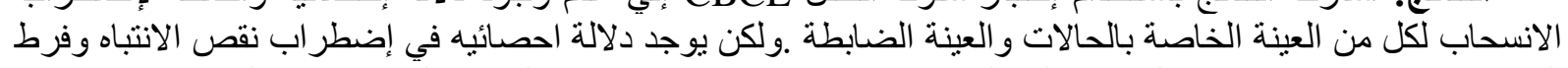

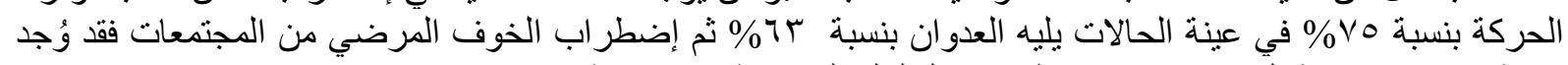

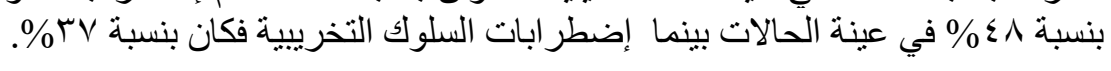

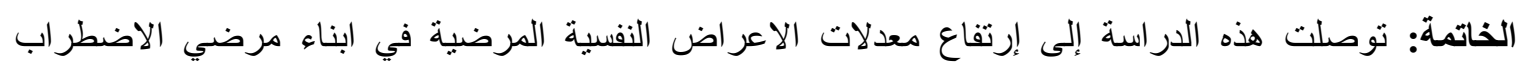

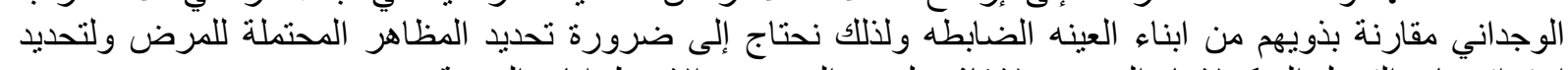

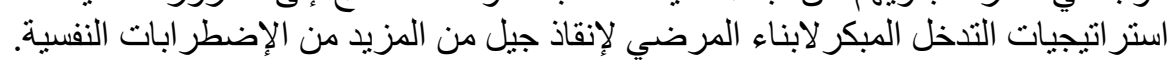

